\title{
Chemical evolution of saline waters in the Jordan-Dead Sea transform and in adjoining areas
}

\author{
Peter Möller · Eliyahu Rosenthal - Stefan Geyer • \\ Akiva Flexer
}

Published online: 5 December 2006

(C) Springer-Verlag 2006

\section{Erratum to: Int J Earth Sci}

DOI: $10.1007 / \mathrm{s} 00531-006-0111-9$

Unfortunately, in the original version of this article Table 1 is incomplete. The first column is missing. The complete table can be found in the following pages.

The online version of the original article can be found at http:// dx.doi.org/10.1007/s00531-006-0111-9.

P. Möller $(\bowtie)$

Geoforschungszentrum Potsdam, Telegrafenberg,

14473 Potsdam, Germany

e-mail: pemoe@gfz-potsdam.de

E. Rosenthal · A. Flexer

Department of Geophysics and Planetary Sciences,

Tel Aviv University, 69978 Tel Aviv, Israel

e-mail: elirose@netvision.net.il

A. Flexer

e-mail: akiva@terra.tau.ac.il

S. Geyer

Centre for Environmental Research, Leipzig-Halle,

Theodor Lieser St. 4, 06120 Halle/Saale, Germany

e-mail: stefan.geyer@hdg.ufz.de 


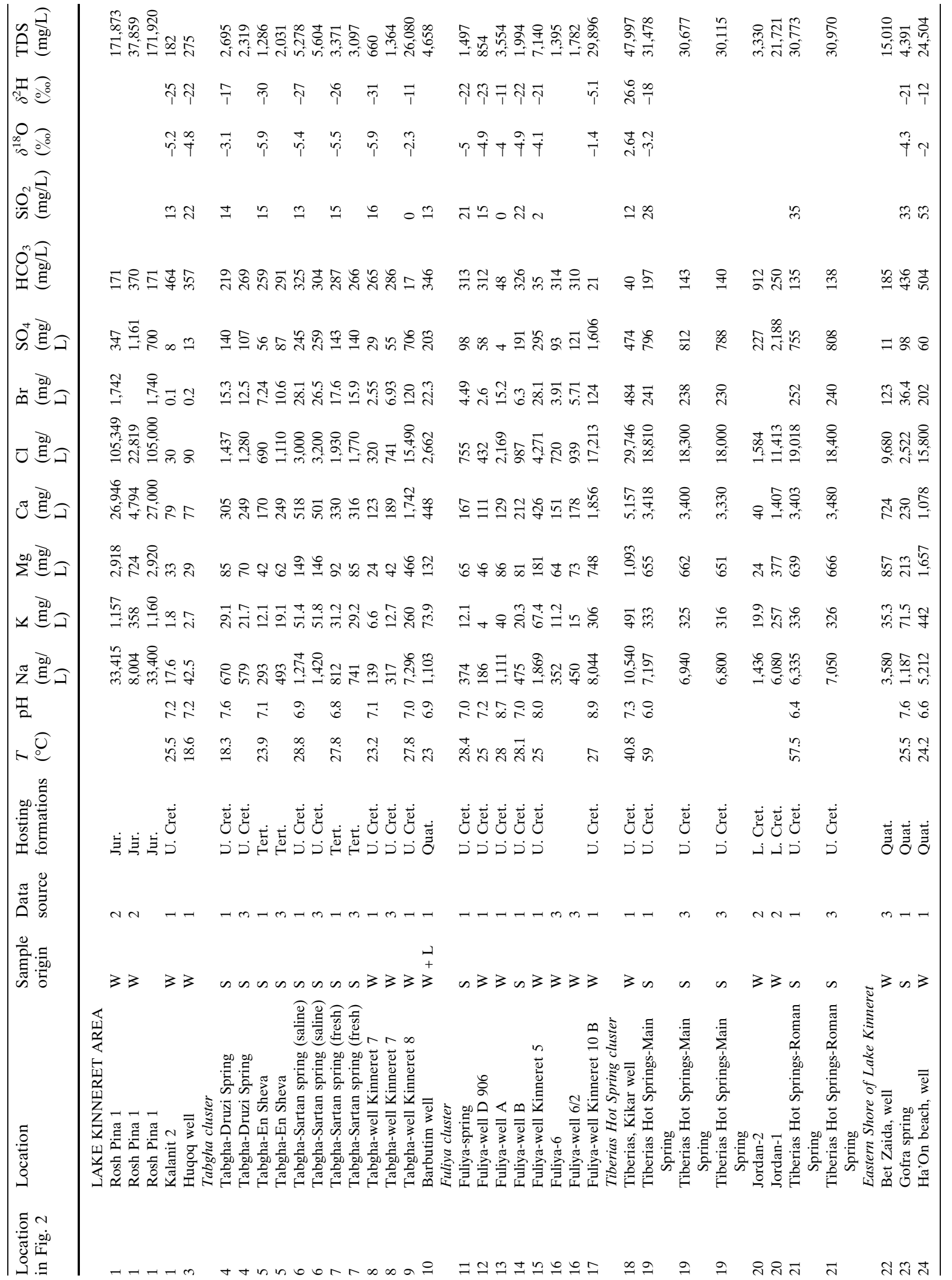




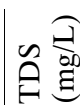
需 $\infty$

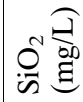

ชำ

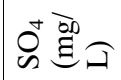

药哭

o暨今

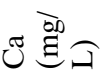

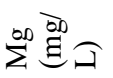

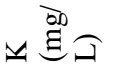

䑰焉

I

$+\frac{0}{0}$

要

总导

竞:

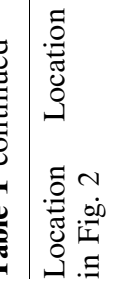

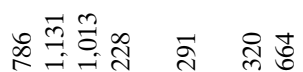
क्रत्रते ते क्ष

宅

ํํำ ำㄴ

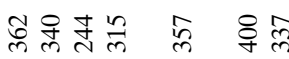

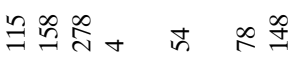

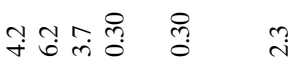

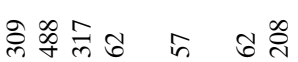

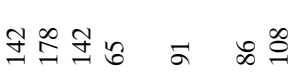

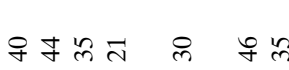

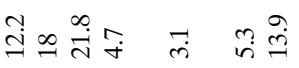

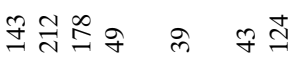

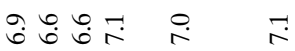

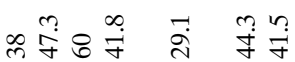

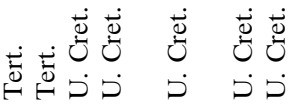

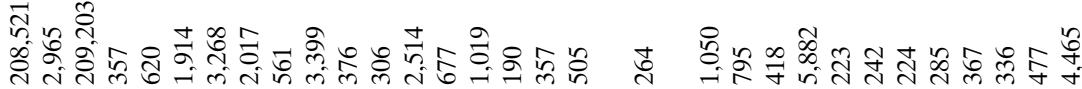

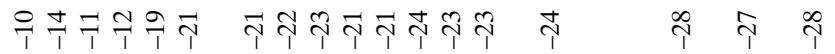

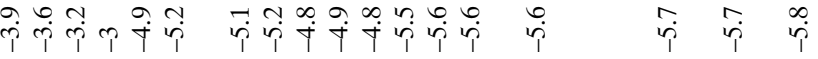

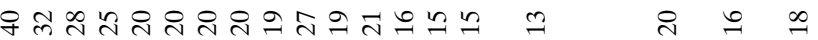

$\stackrel{\infty}{\infty}$

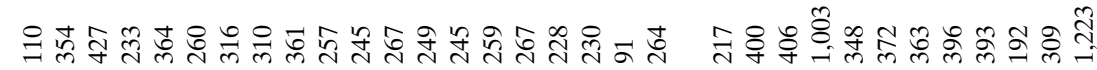

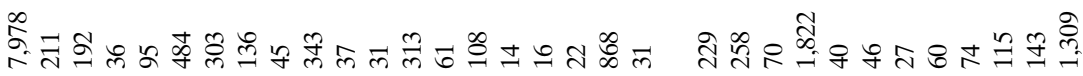

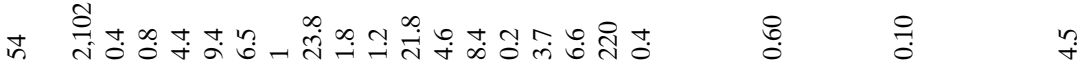

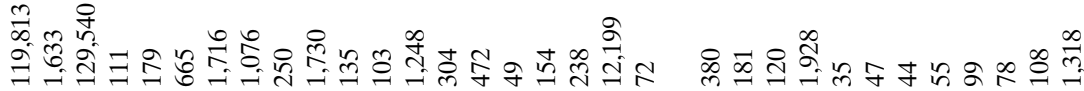

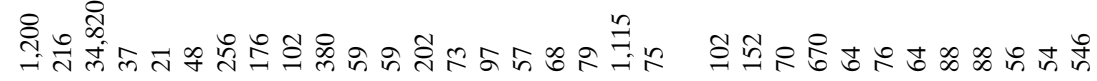

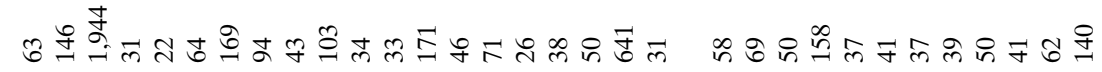

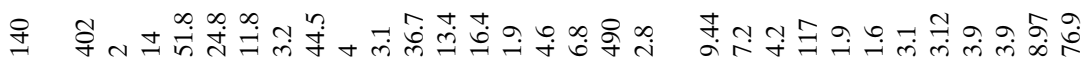

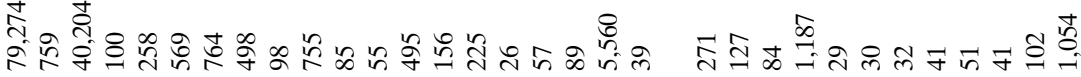

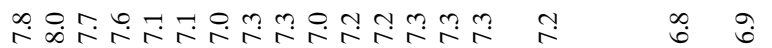

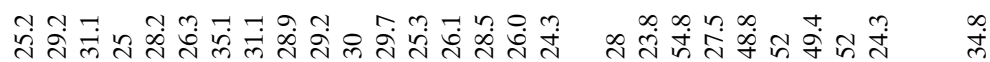

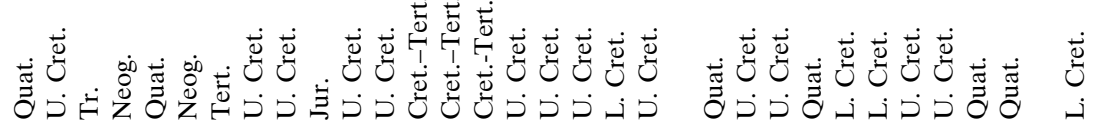

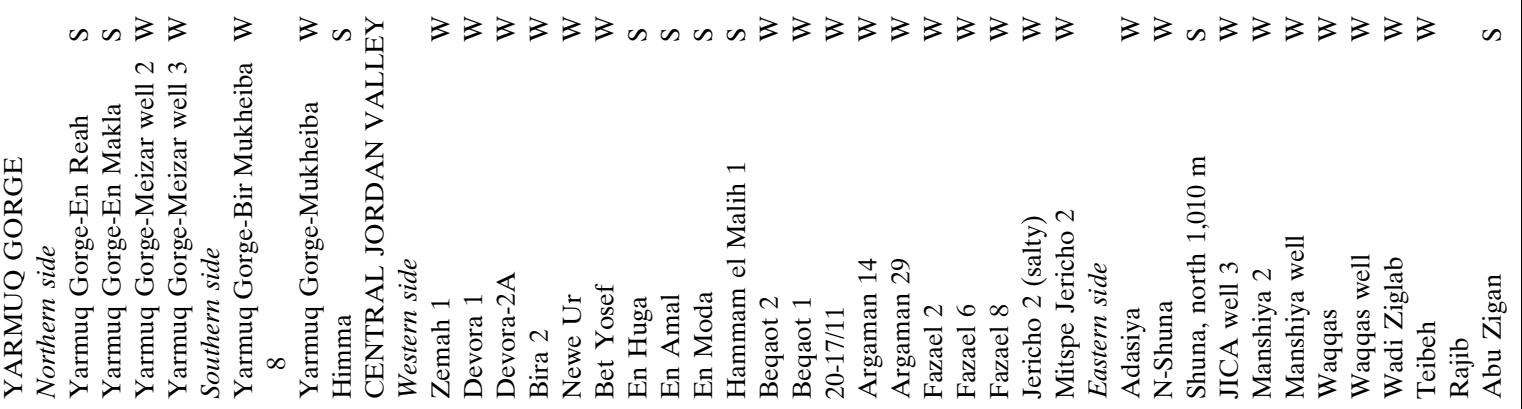
ํํํํำ ำ

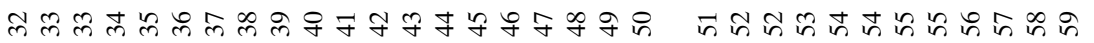




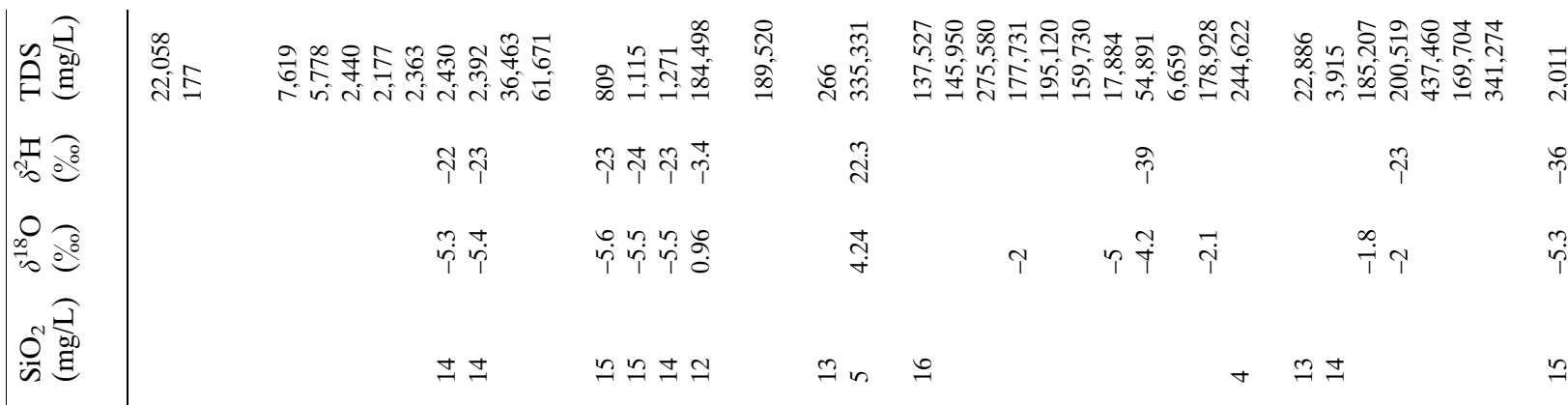

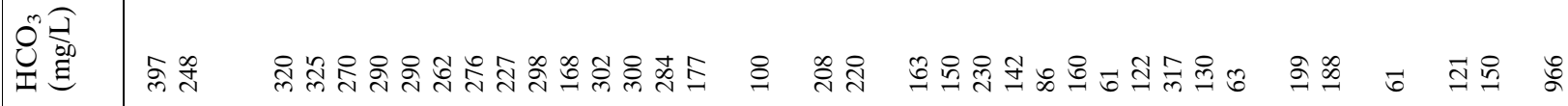

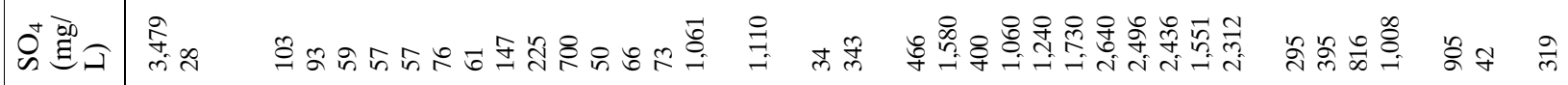

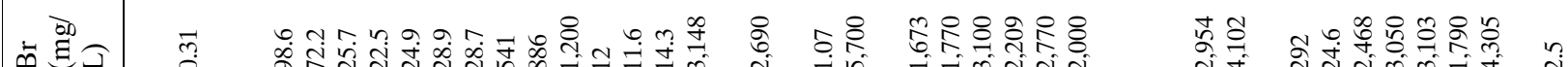
m

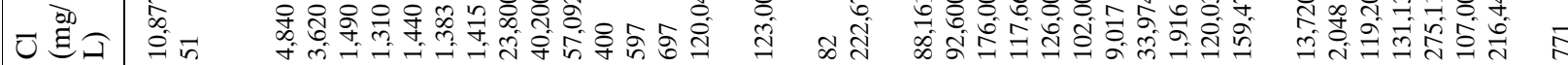
को

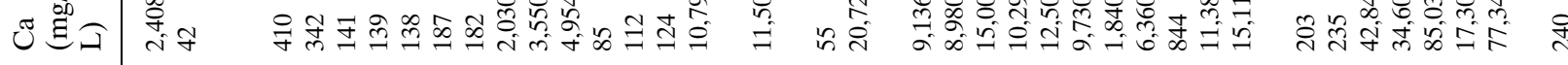

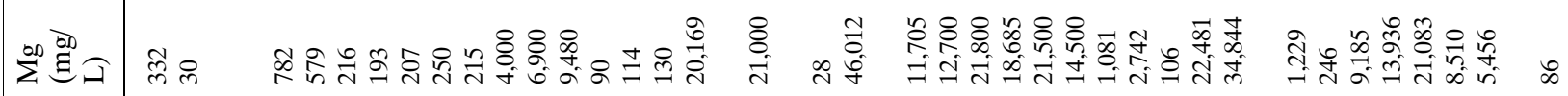

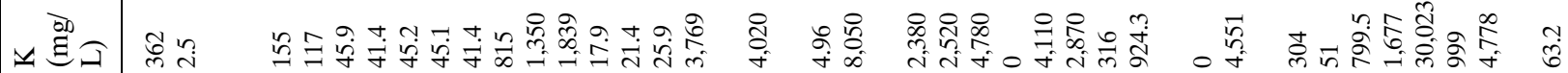

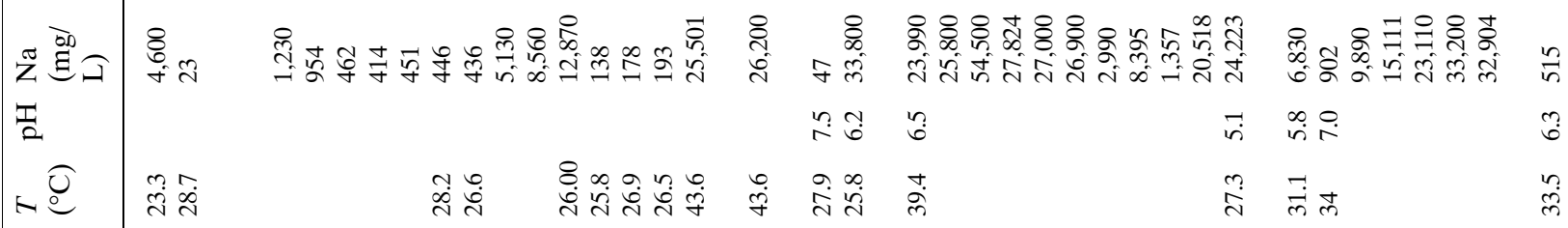

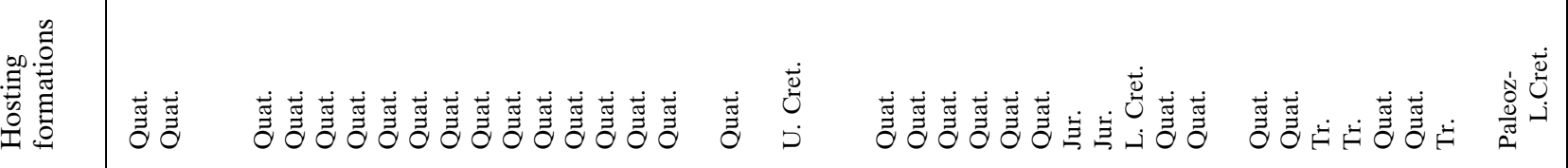
䍃兽

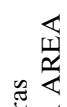

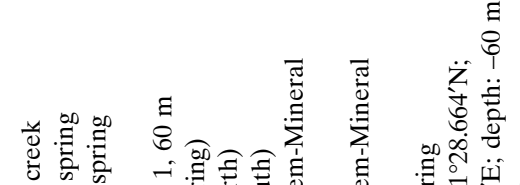

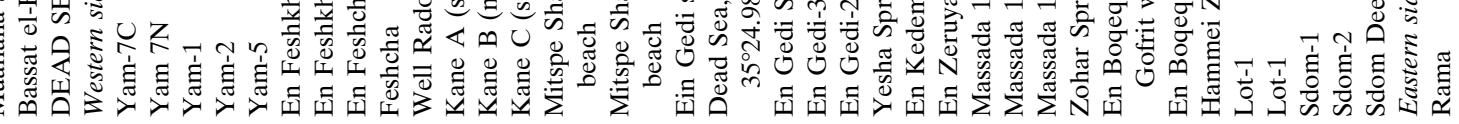

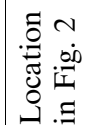




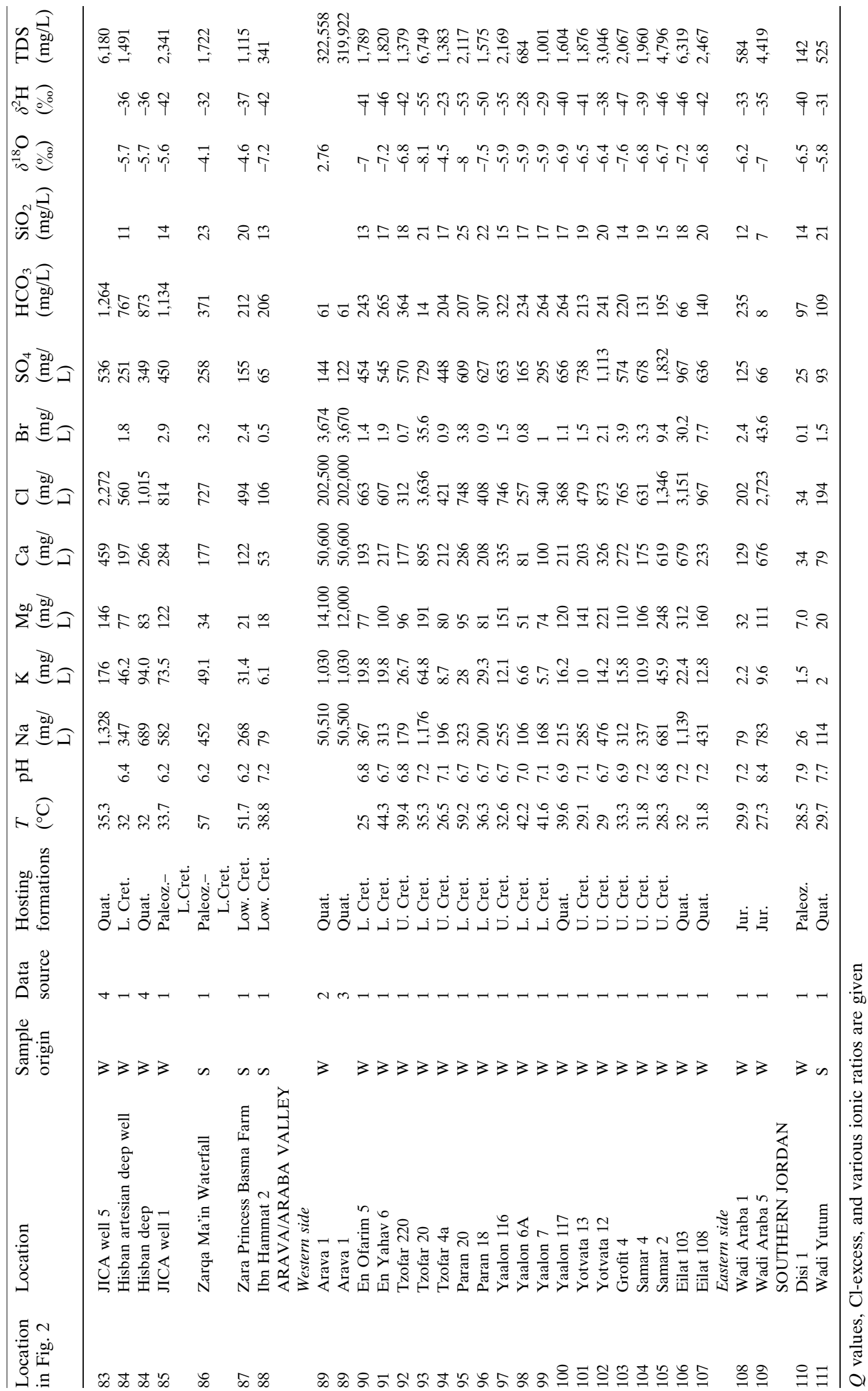

